\title{
DEVELOPING PRODUCTION STRATEGIES USING SIMULATION MODEL ANALYSIS
}

\author{
SERBAN, R[aul] \& CALIN, O[ana] A[ndreea]
}

\begin{abstract}
The developing of production strategies using different types of model analysis can offer information about each activity of an industrial environment. This paper will present a solution for developing production strategies using simulation model analysis. These simulation analyses are including the structural model, the statistic model and the behavioural model. The paper proposes to use one of the presented model or a combination between these three possibilities based on simulation analysis to develop an efficient production strategy. A research direction in this paper is the development of generic models that presents the synchronization between production parameters, objectives, decisions and flow processes.
\end{abstract}

Key words: model, production, strategy, simulation

\section{INTRODUCTION}

The industrial history has realized how important is to study an environment and to predict how the system will operate under a new production strategy.

The aim of this paper is to present a solution for developing production strategies using simulation model analysis. A simulation model analysis could contribute in studying and developing of high performance industrial systems. So it is possible to generate various production strategies and to improve the industrial processes.

Simulation model analysis could be an important aid for planning and monitoring production operations in industrial environments. Simulation process generates information about production strategy development and flow products. Evaluating the flow of the products and the production resources required it is possible to represent the system's structure and select the best manufacturing equipments. The simulation process can be used for a dynamic analysis before the implementation and so it is possible to identify potential areas of congestion which may affect the production system efficiency and also to reduce the costs (Mohora at all, 2009).

The paper will propose a solution for developing production strategies using different types of model analysis. The analyses of these simulation models allow developing a production strategy for every manufacturing resource or for the whole system. The proposed simulation models could offer information about number and type of production resources involved in the manufacturing process. Also it is possible to analyze different production strategies and to choose the best.

\section{MODELING AND SIMULATION TECHNIQUES USED IN A PRODUCTION SYSTEM}

Simulation is the imitation of the operation of a realworld process or system over time. The act of simulating something first requires that a model be developed.

Simulation is well known as a powerful tool supporting the design, layout or re-design of factories and production systems. Recently, many successful applications proved that it can also support the operation of manufacturing systems, especially in the area of scheduling and control.

The model represents the key characteristics or behaviors of the selected physical or abstract system or process. The model represents the system itself, whereas the simulation represents the operation of the system over time. Also in this model we must identify the common measures of system performance:

- Throughput under average and peak loads;

- System cycle time (how long it take to produce one part);

- Utilization of resource, labor, and machines;

- Bottlenecks and choke points;

- Queuing at work locations;

- Queuing and delays caused by material-handling devices and systems;

- Staffing requirements;

- Effectiveness of scheduling systems;

- Effectiveness of control systems.

A simulation of production systems is used mainly to examine the effect of improvements or investments in a production system. Most often this is done using a static spreadsheet with process times and transportation times. For more sophisticated simulations Discrete Event Simulation is used with the advantages to simulate dynamics in the production system. A production system is very much dynamic depending on variations in manufacturing processes, assembly times, machine setups, breaks, breakdowns and small stoppages. 
In general, one can distinguish two ways of using simulation for improving production planning and scheduling:

- A simulation model is used to conFig., test and finetune an existing planning tool. Many planning tools offer a wide range of parameters and option to allow their adaptation to different application areas. However, often the number of possible configurations is so large that even experts cannot predict anymore which is best or even good. A simulation model can be used to test configurations and evaluate their effects on the company's objectives. This way of testing is much faster and less expensive than testing in reality.

- A simulation model is used "online" as part of the planning tool box and run in parallel to the real production process. It can take into account all kinds of rules and constraints and does the bulk of routine work for the human planner.

The complexity of the production problems is increasing and for this reason the paper proposes to use simulation models to develop different production strategies. In many cases using different simulation models we could discover that it is possible to improve production efficiency without incurring any financial investment.

Fig. 1. presents the connection between three important concepts modeling, simulation analysis and simulation languages.

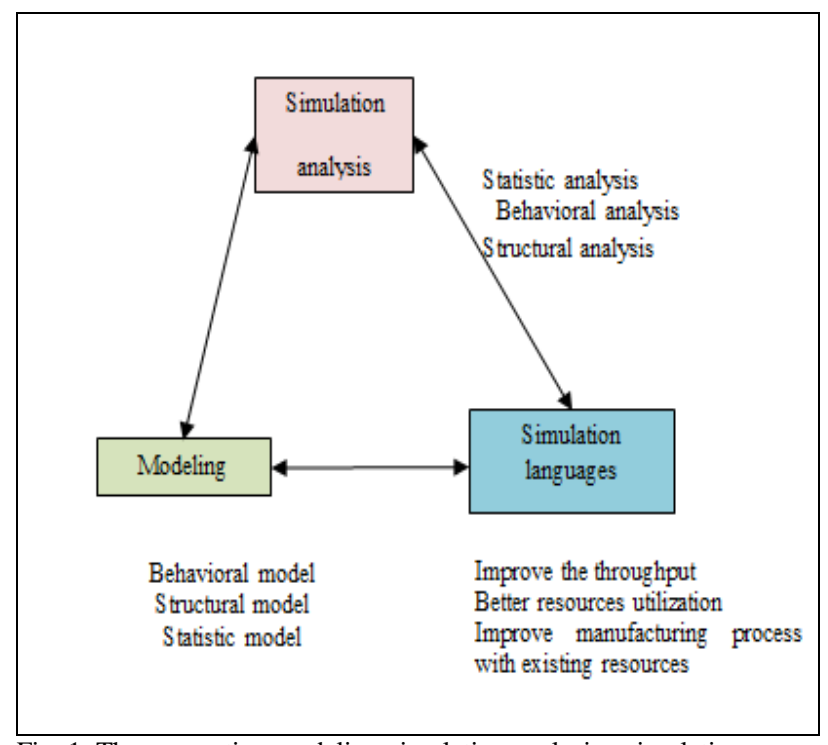

Fig. 1. The connection modeling-simulation analysis - simulation languages

The three simulation models (behavioral, structural and statistic) can be used both as an analysis tool for predicting the effect of a new strategy to an existing production system and also to predict the performance of a new system under varying sets of parameters.

\section{DEVELOPING THE PRODUCTION STRATEGIES USING DIFFERENT SIMULATION MODELS}

An industrial environment could be studied using different production models. The model can be an abstract representation of a production system, containing structural, logical and statistical relationships which describe the industrial processes. The principle objective is to test the impact of a new production strategy on real system using different simulation models.

We shall present three simulation models that include the description of existing production system. These simulation models are including the structural model, the statistic model and the behavioural model. These three selected models are building the models triangle (Fig. 2).

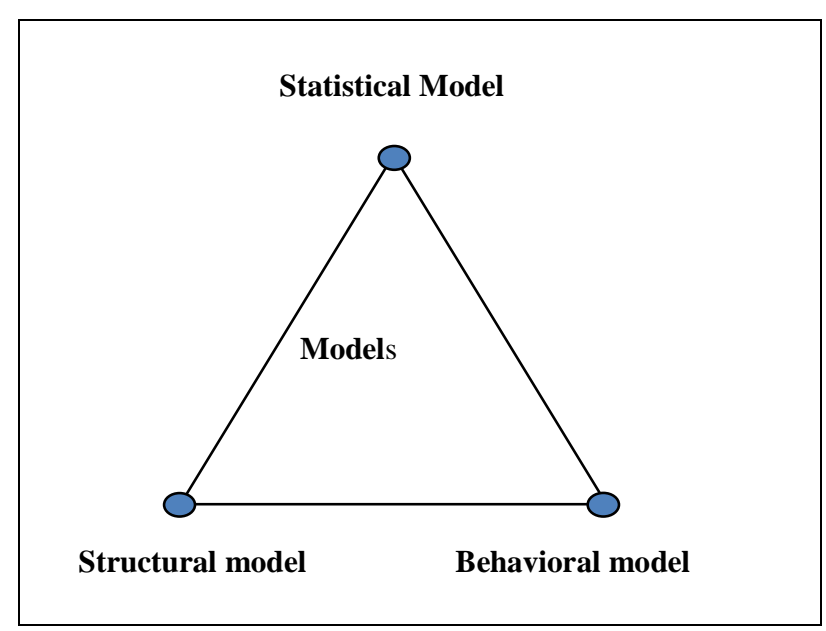

Fig. 2. The models triangle

To develop a production strategy we propose to use one of the presented model or a combination between these three possibilities based on simulation analysis. A model is usually used either to predict system performance or to compare two or more production strategies.

Statistical models are used in modelling of production systems. Because of the random nature of model parameters, a simulation model run will generate a statistical estimation of real performance for production system. The production strategy based on statistical model allows settling the optimum number of parts processed in economical conditions. In this case the variables can be specified and the statistical distributions can be used for specific operations periods. Machine downtime can be scheduled on the basis of operations working time or available time.

Production system structure is an important parameter in process modeling because is useful to see the resources flows and product assembly. The production resources can be machine tools, industrial robots, work posts. So different configurations of the system can be studied and finally the best production strategy will be obtained.

\begin{tabular}{|c|c|c|c|c|}
\hline $\begin{array}{l}\text { Models } \\
\text { Production } \\
\text { strategies }\end{array}$ & $\begin{array}{c}\text { Statistical } \\
\text { analysis }\end{array}$ & $\begin{array}{c}\text { Structural } \\
\text { analysis }\end{array}$ & $\begin{array}{c}\text { Behavior } \\
\text { al } \\
\text { analysis }\end{array}$ & $\begin{array}{l}\text { Estimated } \\
\text { parameters }\end{array}$ \\
\hline
\end{tabular}




\begin{tabular}{|c|c|}
\hline $\begin{array}{l}\text { The } 1^{\text {st }} \text {. } \\
\text { production } \\
\text { strategy }\end{array}$ & $\begin{array}{l}\text { Production } \\
\text { analysis } \\
\text { Utilization } \\
\text { of the } \\
\text { production } \\
\text { resources }\end{array}$ \\
\hline $\begin{array}{l}\text { The } 2^{\text {nd }} \\
\text { production } \\
\text { strategy }\end{array}$ & $\begin{array}{l}\text { Number and } \\
\text { type of } \\
\text { machines } \\
\text { Number and } \\
\text { type of } \\
\text { transporters, } \\
\text { conveyors, } \\
\text { etc. }\end{array}$ \\
\hline $\begin{array}{l}\text { The } 3^{\text {rd }} \\
\text { production } \\
\text { strategy }\end{array}$ & $\begin{array}{l}\text { Time in } \\
\text { system for } \\
\text { parts } \\
\text { Bottleneck } \\
\text { analysis } \\
\text { Control } \\
\text { policies }\end{array}$ \\
\hline $\begin{array}{l}\text { The } 4^{\text {th }} \\
\text { Production } \\
\text { strategy }\end{array}$ & $\begin{array}{c}\text { Throughput } \\
\text { analysis } \\
\text { Number and } \\
\text { type of } \\
\text { transporters, } \\
\text { conveyors, } \\
\text { machines, } \\
\text { pallets etc. }\end{array}$ \\
\hline $\begin{array}{l}\text { The } 5^{\text {th }} \\
\text { production } \\
\text { strategy }\end{array}$ & $\begin{array}{c}\text { Bottleneck } \\
\text { analysis } \\
\text { Control } \\
\text { policies } \\
\text { Queue sizes }\end{array}$ \\
\hline $\begin{array}{l}\text { The } 6^{\text {th }} \\
\text { production } \\
\text { strategy }\end{array}$ & $\begin{array}{c}\text { Number and } \\
\text { type of } \\
\text { machines } \\
\text { Time in } \\
\text { system for } \\
\text { parts } \\
\text { Control } \\
\text { policies }\end{array}$ \\
\hline $\begin{array}{l}\text { The } 7^{\text {th }} \\
\text { Production } \\
\text { strategy }\end{array}$ & $\begin{array}{l}\text { Times parts } \\
\text { spend in } \\
\text { queues } \\
\text { Bottleneck } \\
\text { analysis } \\
\text { Production } \\
\text { scheduling } \\
\text { and } \\
\text { throughput } \\
\text { analysis }\end{array}$ \\
\hline
\end{tabular}

Fig. 3. Developing Production strategies

The analysis of the behavior of the manufacturing system is integrating the Petri nets techniques. Petri nets are a very efficient method to describe and analyze the behavior of a production system. This type of model is suitable for studying the flows during a production process, for the establishment of the system's capacity and for the study of work posts distribution (Ispas at all, 2002).

These combinations and the estimated parameters are presented in Fig. 3 using a code of colors for each type of model analysis. We have used the yellow color for statistical model analysis, the blue color for structural model analysis and the green color for behavioral model analysis.
For every real situation an engineer could choose the right production strategy according to the production necessities and estimated parameters (Serban 2010). The production strategy aided simulation model analysis could evaluate or compare different industrial scenarios and identify the best technical solutions for specified situations. Alternative simulation model analysis is a method used in evaluating production strategies and also may determine whether a manufacturing decision has an important effect. Using the Fig. 3 we can generate a "road map" for production strategies. Fig. 4 will present a graphical representation for all seven production strategies and the connection between these.

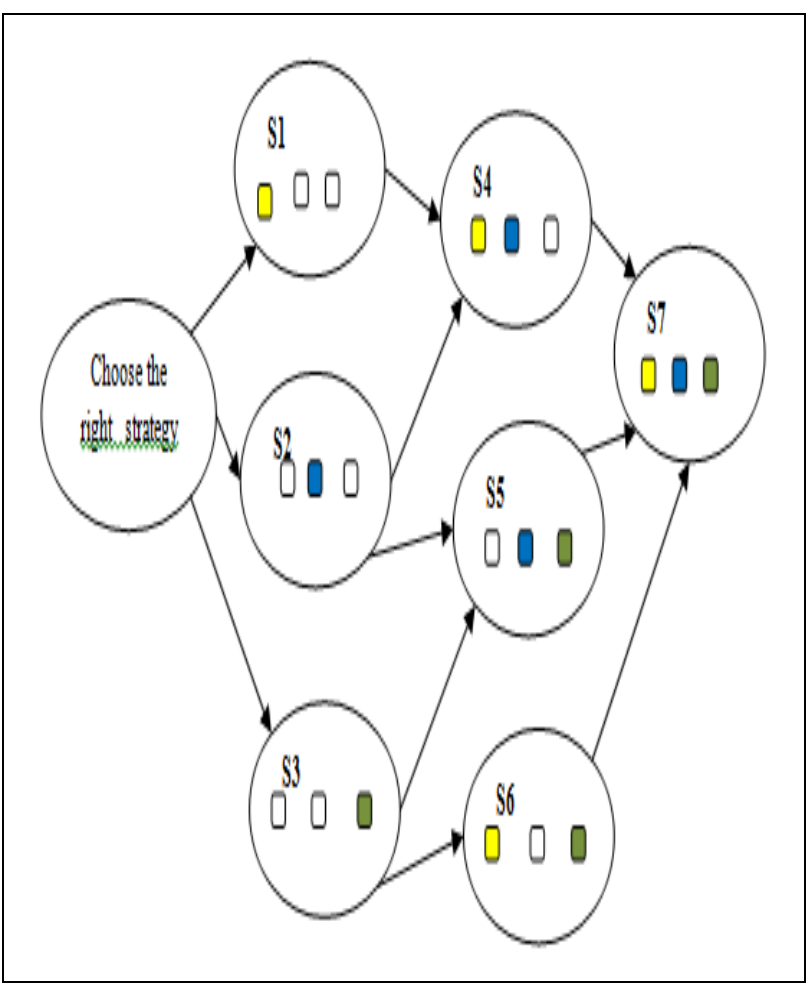

Fig. 4. The production strategies "road map"

Fig. 4 shows a graphical representation using oriented graphs concepts and a code of colors for each type of model analysis. The yellow color is used for statistical model analysis, the blue color for structural model analysis and the green color for behavioral model analysis. The production strategies "road map" is a model that includes all the three types of simulation models.

If we put together all the concepts presented in this paper we will obtain the simulation model that can make a real simulation tool.

Simulation model analysis is a modern method used in evaluating alternative production strategies and also may determine whether a manufacturing decision has an important effect. In addition, the use of the simulation models analysis can result in lower production costs and a higher quality of the products. 


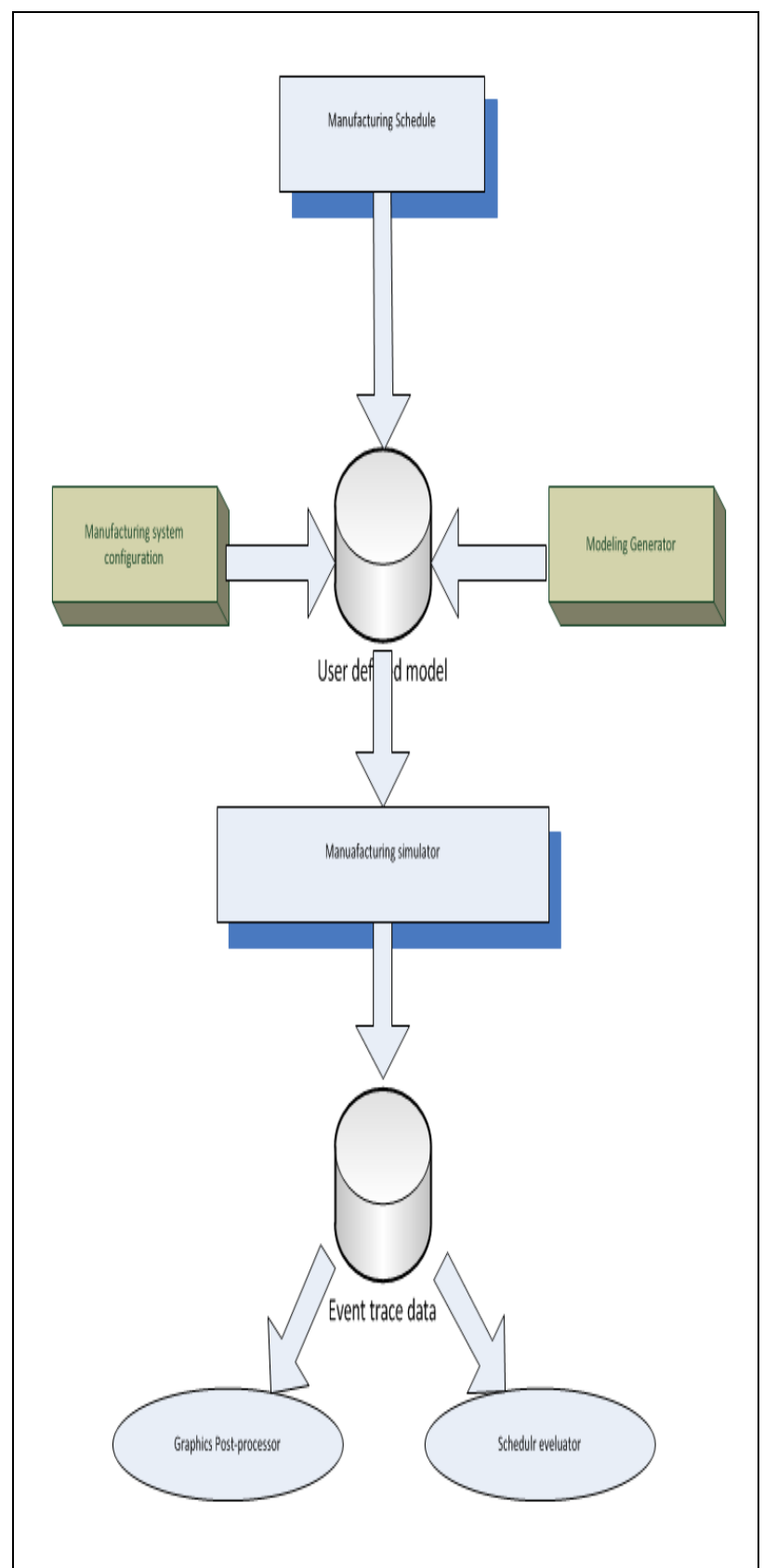

Fig. 5. The production strategies "road map"

\section{CONCLUSIONS}

The production strategies based on different simulation models analysis can be used to generate one or more artificial stories of a production system or to optimize the system. Between the expected advantages when using simulation model analysis there are the high productivity low costs of production and reducing of unproductive time. The paper has presented a method for developing production strategies using three different simulation models analysis. The use of simulation model analysis could significantly reduce the production cycle time and increases the production. The developing of production strategies using the three types of simulation model analysis could also offer information about each production activity in the industrial environment.

We have presented three simulation models types for developing production strategies and for trying to increase the production and efficiency of an existing industrial system. The production strategies based on three simulation models analysis could helped a production environment to achieve significant benefits including:

- $\quad$ better production resources utilization;

- improve the production of an existing industrial system;

- $\quad$ explore of new manufacturing procedures, new decision rules and new organizational procedures.

The three simulation analysis differ by the estimated parameters used by the models and it is particularly useful for example when we are planning complicated work flows or studying different industrial systems.

\section{REFERENCES}

[1] Ispas, C., Mohora, C., Calin, O.A.(2002) Simulation - tool of manufacturing optimisation. Pakistan Journal of Applied Sciences nr. 2, February 2002, Pakistan, ISSN 1607 - 8926, pp. 167 - 169.

[2] Mohora, C.; Anania, D.; Calin O.A. (2009). Simulations strategies using DELMIA Quest, Annals of DAAAM for 2009\&Proceedings of The 20th International DAAAM Symposium "Intelligent Manufacturing \& Automation: Theory, Practice \& Education" 25-28th November, 2009, Vienna, Austria, Volume 20, No.1, ISSN 1726-9679, ISBN 978-3-901509-70-4, pp. 0335-0336, Editor B. Katalinic, Published by DAAAM International, Vienna, Austria

[3] Marek R.P. ;Elkins D.A.; Smith D.R.(2001). Understanding the Fundamentals of Kanban and ONWIP Pull Systems Using Simulation, Proceedings of the 2001 Winter Simulation Conference, pp. 921-929

[4] Kelly C.M.; Mosier C.T; Mahmoodi F(1997). Impact of Maintenance Policies on the Performance of Manufacturing Cells, International Journal of Production Research, pp. 767-787.

[5] Serban R.; Calin O.A. (2011). Production planning strategies using a database integrate system, Annals of DAAAM for 2011\&Proceedings of The 22th International DAAAM Symposium "Intelligent Manufacturing \& Automation: Power of Knowledge and Creativity" 23-26th November, 2011, Vienna, Austria, Volume 22, ISSN 1726-9679, ISBN 978-3-901509-83-4, pp. 1195-1196, Editor B. Katalinic, Published by DAAAM International, Vienna, Austria 